\title{
The Concept of Information Support for Bioresource and Ecosystem Research in the North-West Pacific: Theory and Practical Implementation
}

\author{
Igor V. Volvenko \\ Pacific Research Fisheries Center (TINRO-Center), Vladivostok, Russia \\ Email: volvenko@tinro.ru
}

Received 8 December 2015; accepted 18 January 2016; published 21 January 2016

Copyright (C) 2016 by author and Scientific Research Publishing Inc. This work is licensed under the Creative Commons Attribution International License (CC BY). http://creativecommons.org/licenses/by/4.0/

(c) (i) Open Access

\section{Abstract}

The first part of the article provides an overview of the theoretical evidence, the main provisions, and the implementation strategy of information support for bioresource and ecosystem research in the north-west Pacific, which has been conducted over the past 20 years in the Russian Far East Research Institute TINRO-Center. In short, the concept consists of a combination of the following four assertions: 1) For the steady and sustainable development of the Russian Far East, the entire Russian Federation and the Asia-Pacific Region in general, environmental, food, economic, and other security is required, which cannot be achieved without the rational use of bioresources based on the ecosystem approach to the management of aquatic bioresources. 2) For the inventory, appraisal, monitoring, forecasting of the state of and management the natural water resources when applying this approach, statistically relevant quantitative information is required on the greatest possible number of constituents of marine biocenosis of the northwestern Pacific for the longest possible period of time, which is only available at the TINROCenter. 3) This valuable data should be organized into databases, based on which geo-information and other electronic information systems are prepared, and based on these map atlases and reference books on natural water resources, using automated workplaces created especially for this. 4) The resulting unique information support will be of great value not only for practical purposes, but also for science, both applied and fundamental. Next comes a summary of the many years of work on the practical implementation of this concept and the key achievements in this field obtained by the TINRO-Center by the end of 2015 are reviewed. At the end, some plans for the near future are outlined.

\section{Keywords}

Aquatic Bioresources, Rational Use of Natural Resources, Ecosystem Approach, Information

How to cite this paper: Volvenko, I.V. (2016) The Concept of Information Support for Bioresource and Ecosystem Research in the North-West Pacific: Theory and Practical Implementation. Natural Resources, 7, 40-50. 


\section{Introduction}

Lately, the special role that the Far Eastern seas play in Russia's economy is associated with the discovery of large offshore hydrocarbon reserves, the construction and reconstruction of ports and other coastal production plants, and the building of oil and gas pipelines along the coast and sea bottom [1]. Moreover, the Far Eastern seas and adjacent waters of the Pacific Ocean are a major Russian fishery. This region accounts for just over 2/3 of the total nationwide seafood catch, including marine and fresh water [2]-[7], although according to some estimates [8] [9], 90\% of the resource base of the Russian fisheries is concentrated here.

The study of aquatic biological resources (ABR) in the vast area of the north-west Pacific is one of the main jobs of the Federal State Budgetary Scientific Institution "Pacific Research Fisheries Center" (TINRO-Center). This institute adheres to the ecosystem approach regarding the study and management of ABR [2] [10]-[19], which involves the collection and analysis of data for all groups of animals, emphasizes the interconnections between them, and the role of the climate and hydrological regime in the fluctuations in their numbers. Over the last 40 years, during large-scale comprehensive marine expeditions by the TINRO-Center, a variety of data about the marine biological communities and their abiotic environment has been collated: in an area of water of over 6 million $\mathrm{km}^{2}$, boat and satellite weather observations have been performed, hydrological surveys with deep-sea probes conducted, macrofauna collected with pelagic and bottom trawls with fine-meshed inserts, dredges, bottom-grabs, zooplankton fished out with plankton nets, entire catches sorted by species, counted, weighed, samples made to analyze size frequency, the scales and otoliths of fish analyzed to determine their age; trophological, parasitological, genetic, biochemical and isotopic tests conducted, tagging performed if required, the morphometry of aquatic organisms carried out, marine mammals and seabirds logged, fish egg, gillnet, snurrevaad, longliner, light stations, trapping, diving, and sonar recording carried out, and sometimes sampling of water and soil, and radiological measurements.

Every expedition provides a huge amount of bioresource and environmental information, the compilation and interpretation of which is impossible without compressing it into a format available for analysis by preliminary statistical and cartographic processing on a computer. Modern standardized methods of collecting and processing data require the use of automated workplaces (AW), the accumulation and storage of materials-databases (DB) and their management systems (DBMS), as well as the information systems of the next levelknowledge bases (KB), which operate based not on the original data but on the results of mathematical processing, in particular geographic information systems (GIS) and other electronic reference systems (ERS) (see, for example [20]). Most of the work to develop and operate them over the past 20 years at the TINRO-Center has been conducted in a structured and goal-oriented fashion, in accordance with the concept of information support for bioresource and ecosystem research in the north-west Pacific (hereinafter referred to as CIS for short).

\section{The Theoretical Provisions of the Concept}

It is crucially important that the stated concept is inextricably linked to a whole set of other fundamental ideas and documents of our times (Figure 1) - the concepts, issues, problems, approaches, trends, integrated programs, conventions, strategies, doctrines - integral to it and even forms its basis. Let us examine this in more detail.

The effective protection of rare and endangered species, the preservation of biodiversity, the fight to reduce environmental pollution, including biological (invasive species), regulated fishing, particularly multi-species fishing, and the artificial reproduction of aquatic and land reclamation habitats are possible only within the framework of the ecosystem approach to the study and management of bioresources. This approach is a component of the concept of rational use of natural resources [19].

Specialists in this interdisciplinary field say that bioresource exploitation, which leads to exhaustion and even extinction of bioresources, environmental pollution, and ecological imbalance of natural systems, i.e. an environmental crisis or a catastrophe, is considered irrational (unsustainable) [21]. Its alternative is rational (sustainable) use of natural resources—a "working system, designed to ensure the economic exploitation of biore- 


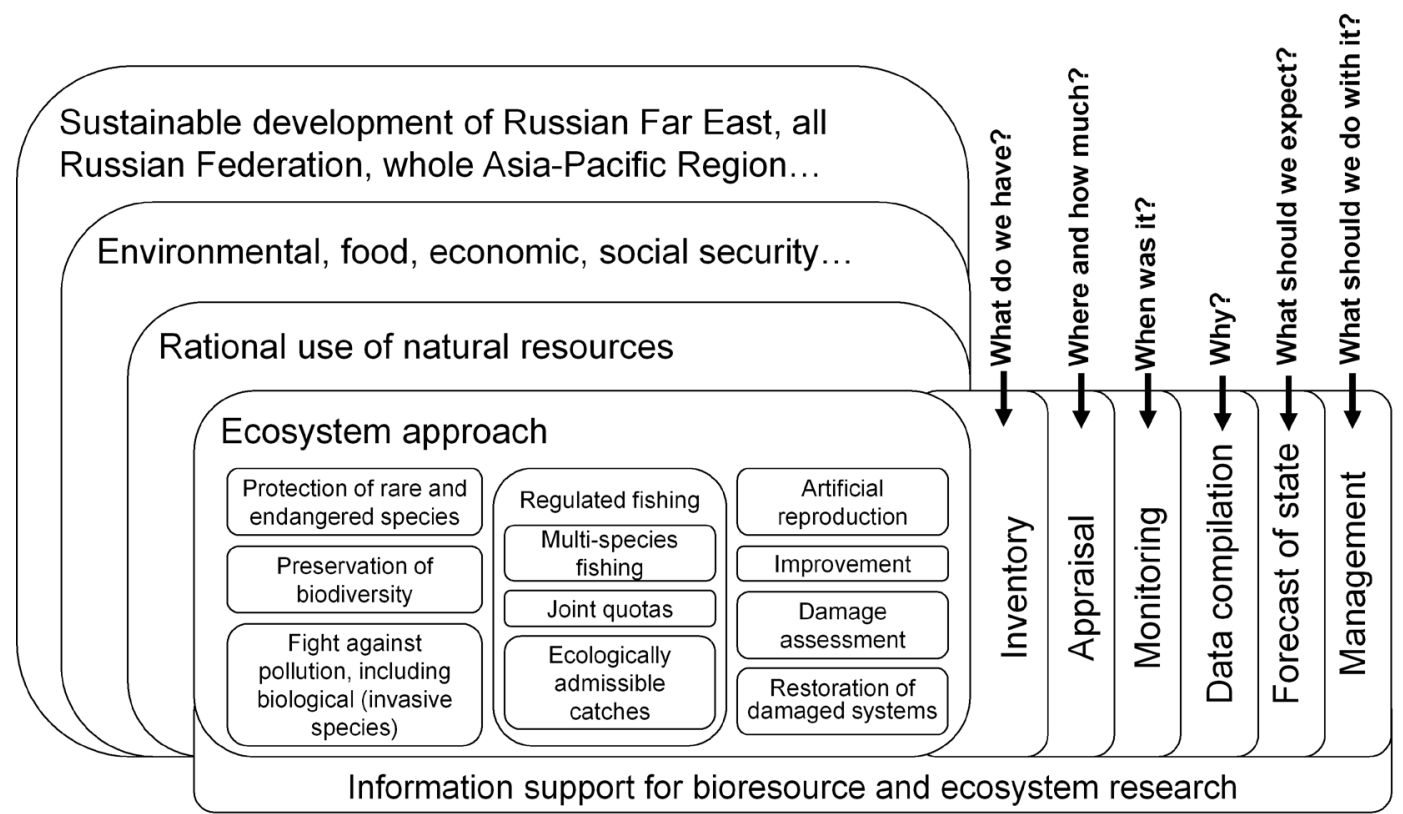

Figure 1. The combination of interconnected ideas (vertical), which includes as its basic component the concept of information support for bioresource and ecosystem research of the north-west Pacific, as well as a range of activities with respect to ABR (horizontal) necessary to implement these ideas.

sources and the environment so that it can regenerate quickly and taking into account the long-term interests of the developing economy and the protection of human health.” [22]. According to E. Odum [23], sustainable use of natural resources ensures an environment in which we can meet our material needs while aesthetic and recreational requirement are met, and at the same time allow the continuous production of crops, and the production of a variety of materials through the establishment of a balanced life cycle and renewal. Such an ecologically balanced use of bioresources is only possible when applying the ecosystem approach, taking into account all kinds of relationships and interconnections between the environment, biocenosis and people. Only the ecosystem approach provides a credible rationale for sustainable use of natural resources [24].

Rational environmental exploitation, in turn, is a prerequisite for environmental security. According to the definition adopted in Russia (Federal Law No. 7-FZ “On Environmental Protection”, dated 10/01/2002 (ed. dated 25/06/2012)), environmental security means the environment and the vital interests of people protected from the possible negative impact of economic and other activities, natural and man-made disasters and their consequences. To ensure environmental security in this region, in 2007, the Far Eastern Branch of the Russian Academy of Sciences (FEB RAS), together with a number of other scientific and industrial organizations, developed a comprehensive program called "Modern environmental safety technologies for the Far Eastern seas for the sustainable socio-economic development of the Far East and Russia and effective Russian geopolitics in the Asia-Pacific region" [1] [25]-[27]. As the title of this program and the above definition suggest, "environmental security" refers to a range of interrelated food, economic, social security problems, etc. Therefore, many countries have included issues about environmental security in their national (state) security strategies. In particular, National Security Doctrine of the Russian Federation up to the year 2020, approved by Presidential Decree No. 537 on 12/05/09, contains the strategic objectives of environmental conservation and environmental management. Moreover, international non-governmental organizations have sprung up, which are involved in collecting data on environmental security, such as the Institute of Economic Security (IES), The Foundation for Environmental Security and Sustainability (FESS), and others [28].

Now let us direct our attention to the fact that this implies the need to respect all possible aspects of security associated with the environment, for the sustainable development of the Far East, Russia, Asia-Pacific, etc. In 1992, the United Nations Conference on Environment and Development (UNCED) officially recognized the harm in the traditional ways of developing the global community, which has been described as unsustainable development, fraught with crises, catastrophes, and the death of all living things. A definition from the Brundt- 
land Report "Our Common Future” [29] was widely used at UNCED: sustainable development is a form of development that meets the needs of the present, but does not compromise the ability of future generations to meet their own needs [30] [31]. Of course, the idea of sustainable development is more than just rational use of natural resources, since sustainable development requires not only a sensible approach to bioresource management, but also to other economic, political, and cultural issues, etc.

From everything stated above, it is evident that long-term, continuous, sustainable development requires security, which cannot be achieved without environmental exploitation based on the ecosystem approach to the management of ABR.

To find solutions to a variety of related tasks, a set of measures must be implemented (see Figure 1), including inventory, assessment, monitoring, and collation of data for the prediction of the status and management of ABR. These measures involve finding answers to a variety of questions, such as what do we have, when, where, and how much, why, what should we expect in the future and finally - what should we do with it? To make the right decisions about what can and should be done with ABR we need information that is collected in accordance with the ecosystem approach, information that is stored, structured, and specially processed. Naturally, this information must be statistically significant and there must be quite a lot of it. From the above-mentioned we can say that without a database and knowledge base created especially for this, neither rational use of natural resources, nor security or sustainable development are possible. The presence and constant updating of such strategic data banks is particularly relevant in view of the fact that there is still a number of reasons the theoretical prediction of trends in marine ecosystems is still very difficult and requires constant comprehensive monitoring in ecosystems of different scales [5] [19] [25].

Let us note, however, that none of the above-mentioned policy and regulatory documents, such as the proposed set of measures by FEB RAS (see [1] [25]-[27]) to ensure security and sustainable development in Russia, envisage the establishment and operation of the database and knowledge base with the materials of the long-term monitoring of the status of marine and ocean ecosystems. The latter is not surprising, since the FEB and all of RAS do not possess such data nor the technical capabilities to collect it (above all, a fleet). Such a significant gap in efficient environmental exploitation, security, and sustainable development of the Russian Federation is only possible to fill through the ongoing work at the TINRO over the past few decades.

It was mentioned above that among the main applied tasks of this institution is the monitoring and forecasting of the state of the resource base of domestic fisheries, and any estimates and projections, be they model or expert, are always based on certain quantity of data-the actual observation of natural phenomena and processes. The rule usually applies that the more raw data, the better the prognosis. For example, the statistical analysis of cyclical fluctuations in populations requires a time series analyses of observations that is at least 2 times longer than the duration of one cycle (see, for example [32]). Figuratively speaking, based on the raw data-the "cornerstone" on which the conclusions concerning the current status of biological resources and forecasting of their future state lie, estimates are made of the total allowable catch (TAC), possible catch (PC), and other parameters of efficient bioresource exploitation [33] [34]. Therefore, in their many marine expeditions over the years the TINRO-Center employees have always strived to produce as much primary data as possible.

However, when creating a new database for the information support of not only the bioresource, but ecosystem studies, it is necessary to collate not just the maximum amount of expedition data or a series of observations for as long as possible of an individual dominant and commercial species, but only the data that contains complete details of all marine and ocean biocenotic groups without exception. Such data is required for the rational use of biological resources and their ecosystem-based management, since the population of commercial species do not live in isolation, but within communities (biocenosis). The biocenologic background for them is the same habitat as the hydrological regime. This is important to understand and predict changes to the state of biological resources in general and also the fisheries resource base [5]. Figuratively speaking, "even the autecological detailed understanding of fishing grounds is only the visible tip of the iceberg, the bulk of which remains invisible under the water. But it is the impact of the currents, not the surface wind that determines the path of the iceberg. This underwater part represents the very biocenosis and ecosystems, which include commercial hydrobionts as its components" [19].

The acquisition of expedition data that satisfies these requirements, from all possible sources should lead to the creation of a minimum of three databases: the pelagic and bottom trawl macrofauna and net zooplanktonmesofauna (Figure 2). Macrofauna in this case refers to animals with a body size from $1 \mathrm{~cm}$ to several meters and weighing from grams to several hundred kilograms. In fact, this means all the animals that are harvested 


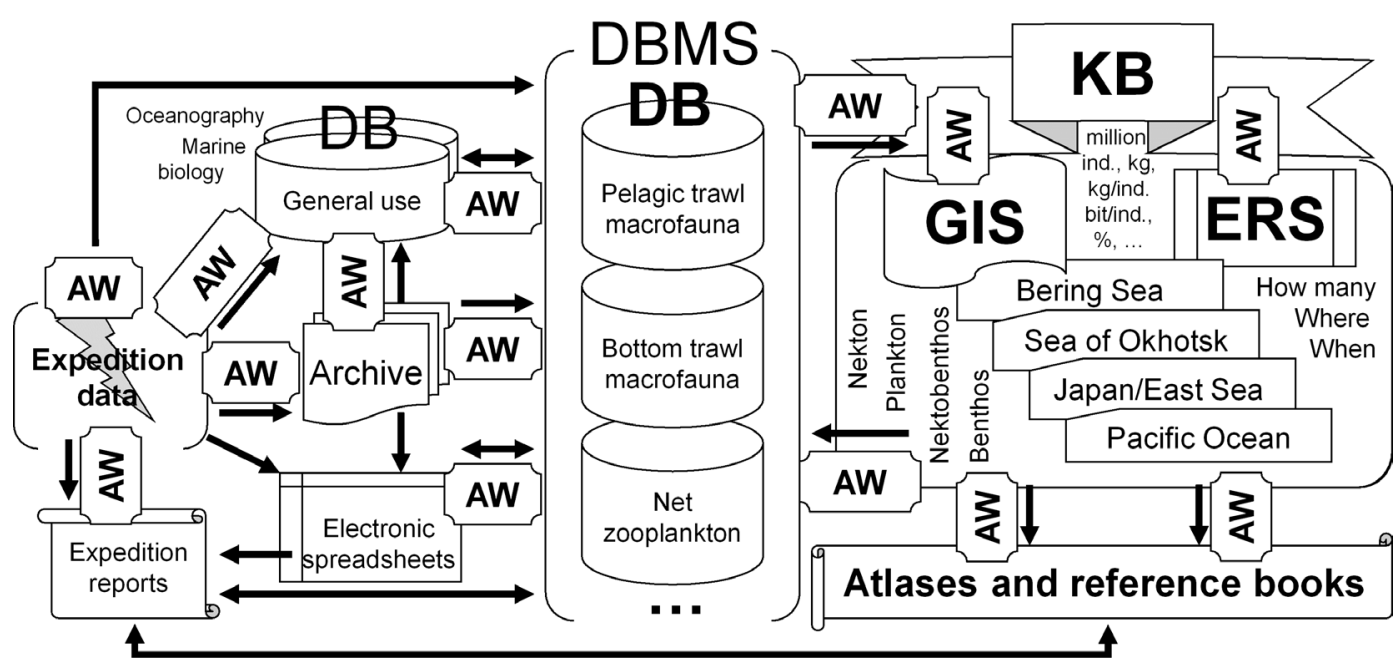

Figure 2. Schematic diagram of the implementation of the concept of information support for bioresource and ecosystem research in the north-western Pacific. Legend: DB — database, DBMS — database management systems, KB-knowledge base, GIS-geographic information system, ERS—electronic reference systems, AW—automated workplaces, Archive-storage of expedition data on paper. The arrows indicate the flow of information.

by a trawler equipped with a fine-meshed insertion from 10 - 12-millimeter netting. Macrofauna includes commercial animals, and their food, predators, competitors, parasites, symbionts, etc. Mesofauna, caught by a plankton net are organisms with a lower body size and weighing hundredths or thousandths of a milligram — mostly the food supply and larvae of invertebrates and fish. The largest animals-megafauna-if we do not count sharks and giant squid, are whales weighing several tons. These as well as other mammals and sea birds play an important role in ecosystems [35] [36], but reliable quantitative estimates of the population density in the vast sea areas are very few: their occasional visual surveys cannot be compared with large-scale trawl and plankton surveys regularly supplying massive amounts of fairly accurate data on the abundance of the rest of the fauna. The smallest organisms are micro- and nano-flora and fauna-producers and decomposers, are unfortunately too rarely taken into account by these surveys because of the complexity of processing the samples and the absence of the necessary specialists.

Following the organization of the DB, the natural step is to create high quality information products based on it - KB about the ABR, which will contain not the original raw data but the results of their statistical and cartographic analysis (see Figure 2). This work is planned to be performed in two areas: 1) the cartographic description of the features of the spatio-temporal distribution of animals; 2 ) the quantitative evaluation of the occurrence, population density, gross stocks, and the species composition of the ABR. In the first area of work the GIS needs to be prepared containing a large number of electronic maps with the spatial distribution of aquatic organisms and atlases published of the quantitative distribution of mass and ecologically or economically important species with the most interesting and illustrative maps for each sea and/or the entire north-western Pacific. In the second area of work an ERS needs to be created with statistical tables of various indicators of the abundance of absolutely all aquatic species, the details of which entered the database, and corresponding spreadsheet appendixes need to be published with the atlases and/or individual reference books. This part of the work is important in itself, and in addition it will contribute to the further verification and refinement of the data collated in the database.

Naturally, this work requires the development of AW—specialized software systems (see Figure 2) in order to perform the routine tasks of inputting, checking, editing, converting and analysing information. The information system created as a result will make it possible to evaluate the density and gross reserves of hundreds of fishing and mariculture objects in the north-western Pacific areas, the spatio-temporal dynamics of the ABR and the state of their ecosystems. It will enable a number of important hypotheses to be tested, for example, about man-made global warming and its possible implications for the fishery industry. Information about the natural state of the marine biocenosis is gaining particular importance today in view of the expansion of the exploration of non-renewable resources (oil and gas) on the Russian shelf, and other types of water pollution. The data collected will form the basis for comparative environmental impact assessments, the evaluation of any possible en- 
vironmental damage, decision-making on the need for environmental protection and rehabilitation measures. This data is valuable material for fundamental research in ecology and biogeography in order for us to extend our theoretical ideas about the basic principles of the organization of life in the oceans.

Briefly, CIS is formulated in the form of four main provisions:

1. For the steady sustainable development of the Far East, Russia, and the Asia-Pacific region, environmental, food, economic (etc.) security is required, which cannot be achieved without the rational use of bioresources based on the ecosystem approach to the management of ABR.

2. For the inventory, appraisal, monitoring, forecasting of the state of and management the ABR when applying this approach, statistically relevant quantitative information is required on the greatest possible number of constituents of marine biocenosis of the north-western Pacific for the longest possible period of time, which is only available at the TINRO-Center.

3. This valuable information should be organized in DB, on which basis the GIS and ERS are prepared, and based on them ABR map atlases and reference books, using an AW especially created for this.

4. The resulting unique information support will be of great value not only for practical purposes, but also for science, both applied and fundamental.

\section{The Practical Implementation of the Concept}

More information about the history, the main results and prospects of CIS were recently published in the journal "Trudy VNIRO" in a series of three large papers [37]-[39]. Here, we pay attention to just a few key points in which theory has been put into practice over the last 20 years.

To date, the TINRO-Center has created all the AW shown in Figure 2. As a result, at the end of the 1990s the first version of the database of pelagic trawl macrofauna was created and then considerably augmented and improved [40]. After this, in 2011-2013 a similar database of benthic trawl macrofauna [41] was made. In 20142015, a net zooplankton database was created (detailed information on it will be published soon in the journal “Izvestiya TINRO”). The first database contains data from 32,264 stations collated from 24/12/1979 to 31/10/2014, the second-36,640 stations from 26/04/1977 to 10/31/2014, and the third-25,512 stations from 27/04/1984 to 20/11/2013 in the North Pacific Ocean and adjacent seas: the Chukchi, Bering, Okhotsk, and Japan/East seas (Figure 3). In addition to information on the number and biomass of each species of aquatic animals at each station, the first database contains size data of 5,880,845 measured individuals and 72,016 subjected to biological analyses, the second - 3,901,386 measurements and 269,774 analyses. Now the new data are being inputted into the databases that were collated during expeditions in 2014-2015.

By themselves, the two first databases during the implementation of CIS were the starting point for many methodological innovations, and they played a key role in identifying a number of general ecological and biogeographical regularities, including those with important applied implications for fisheries (for examples of numerous articles, monographs and dissertations, which would not have been possible to write without these databases, see [38] [39]). However, on their basis objects were created, shown on the right in Figure 2. These are KB including several GIS (see, for example: [42]-[45]), which are taken from thousands of maps published from 2003-2006 in the form of atlases of the nekton in the Far Eastern Seas and the North-Western Pacific Ocean [46]-[49] (top row of the books in Figure 4). Spreadsheet appendixes were published along with the atlases [50]-[53] (second from top row in Figure 4). In 2012, similar reference tables were published, containing updated and expanded information not only about nekton, but about all the pelagic macrofauna [54]-[56] (third from top row in Figure 4), and in 2014 this was done for benthic macrofauna [57]-[61] (bottom row in Figure 4).

In 2003-2014, the TINRO-Center published 12 monographs-reference books [50]-[61] totalling 7187 pages, and containing the results of a survey of the maritime exclusive economic zone of Russia and adjacent waters. These tables contain detailed information on the composition and abundance of the entire pelagic, bottom and near-bottom macrofauna of the surveyed waters. This includes the occurrence and abundance of each species on average over the entire observation period, over the four seasons (winter, spring, summer, autumn) and four long-term time periods, with different climatic and oceanographic conditions and biological resource status. The data are compiled in 48 standard areas (see Figure 3). In addition to the pelagic population, the data are grouped into three water layers: epipelagic (the headline horizon $\leq 200)$, upper epipelagic $(\leq 50)$ and mezopelagic $(\geq 200$ $\mathrm{m})$; and for the inhabitants of the bottom—eight bathymetric zones with depths of $<50,50-100,100-200$, 


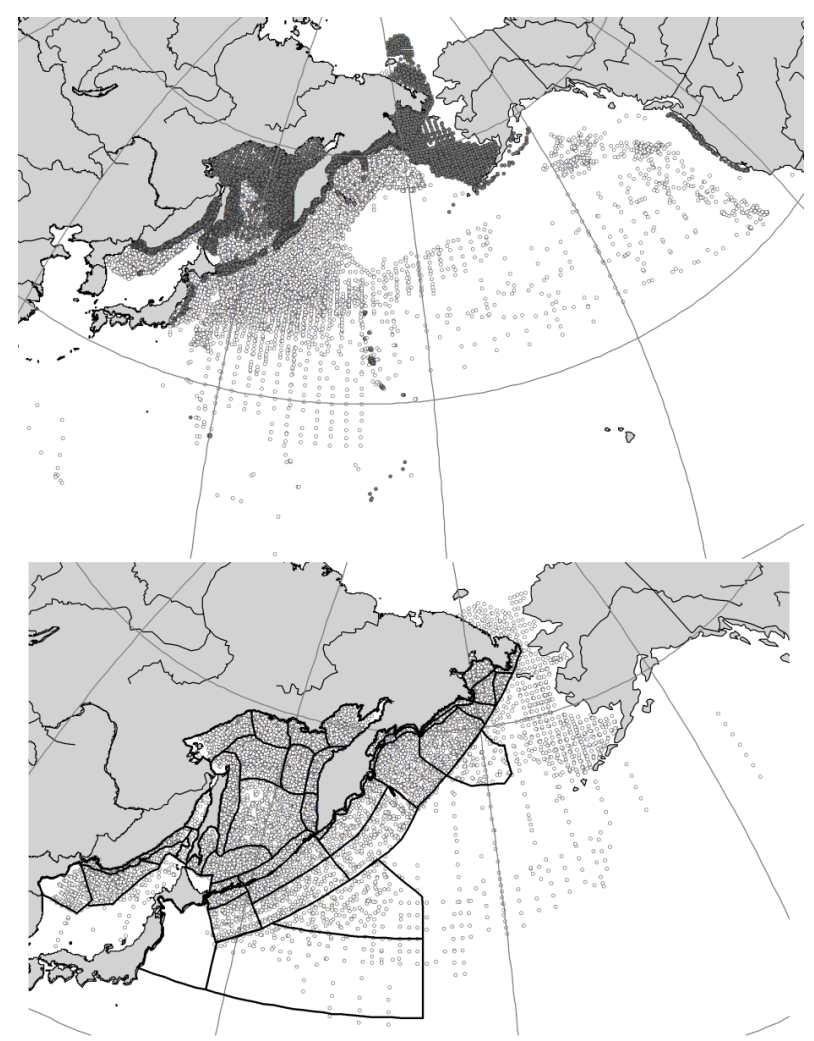

Figure 3. The spatial location of stations from which data was inputted into the databases: on the top map-pelagic (light) and bottom (dark circles) of trawl stations; on the bottom-plankton stations. On bottom map the water area that was constantly monitored is marked by bold lines, divided into 48 regions in which biostatistical information was compiled.

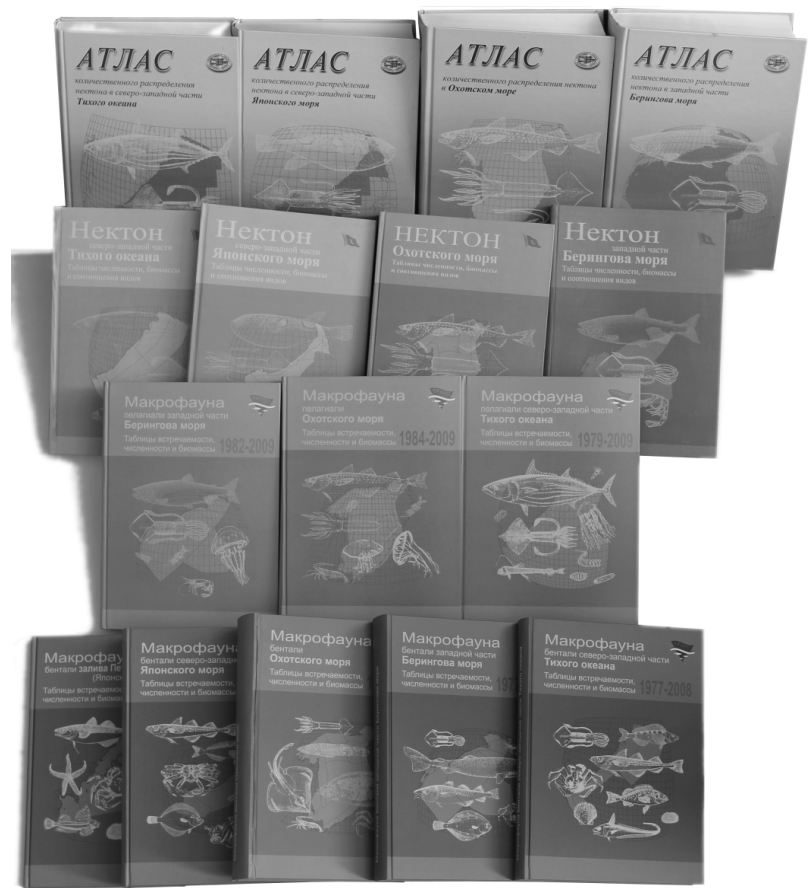

Figure 4. Atlases and reference books, published by the TINRO-Center in 2003-2014 in the implementation of the concept of information support for bioresource and ecosystem research in the north-western Pacific. Electronic files are available on the website http://www.researchgate.net. 
200 - 300, 300 - 500, 500 - 700, 700 - 1000 and 1000 - $2000 \mathrm{~m}$. For the well-studied abundant species, all the information is given separately for three size-age groups: small/larva, medium/juveniles and large/adults. In the final lines of the tables for the pelagic macrofauna the total abundance of fish, cephalopods, crustaceans, nekton, jellyfish, comb jellies, nudibranch and all macrofauna are listed, and for the bottom macrofauna—all fish, gastropods, bivalves, shrimps and prawns, crabs and king crabs, sea urchins, sea cucumbers, jellyfish and comb jellies, all invertebrates and all macrofauna are listed. Together, they provide the opportunity to measure the population density and gross stocks (as well as its seasonal and inter-annual changes) of any of the ABR of the Far Eastern Seas and the North-Western Pacific Ocean. What is important is that all the tables contain detailed information not only on commercial and potentially commercial animals, but also about their biocenotic environment-all the other species - from dominant to indicator, endemic, rare and endangered. This is a unique basis for future comparisons in monitoring the ecosystems of the north-western Pacific, which is especially important in view of global climate change, and the above-mentioned expansion of oil and gas exploration on the shelf of the region.

In October 2015 at the 24th Annual Conference of The North Pacific Marine Science Organization (PICES), the series from these twelve monographs and reference books was awarded the prestigious international award "PICES Ocean Monitoring Service Award (POMA)"

(http://www.pices.int/awards/POMA award/2015-POMA/2015-POMA.aspx). For the first time in the history of the organization, Russian scientists were recognised for their significant contribution to the study of the North Pacific. The official website of the Federal Agency for Fisheries of the Russian Federation states in this regard (http://www.fish.gov.ru/press-tsentr/novosti/8522-mnogoletnie-issledovaniya-uchenykh-tinro-zasluzhili-priznani e-mezhdunarodnogo-nauchnogo-soobshchestva-pices): “Our foreign colleagues recognize that such comprehensive ecosystem research is not regularly conducted by any Pacific power, and no country has a database of this scale other than Russia. This allows Russia and, in particular, the TINRO-Center to play an important role in the study of the Pacific Ocean and the inventory management of its biological resources."

In continuation of the CIS implementation, at the end of 2015, five new similar reference books on net zooplankton [62]-[66] were put into the publishing house, and in 2016 plans are in place to create a GIS and prepare the original layout of the spatial and temporal distribution maps of plankton in the Far Eastern seas and the north-western Pacific.

With sufficient funding to perform the CIS work, it is expected to resume publication of the pelagic and bottom macrofauna atlases in new formats - so that each map displays not only one sea or the north-western Pacific (as in the first atlases [46]-[49]), but instead all the surveyed water areas (similar to that shown in Figure 3).

In addition, for several years present-day and historical data has been added to the database "Observations of marine mammals", but it is not yet available and therefore not shown in Figure 2. It contains a description of the observations made by seaman in the scientific and commercial (mostly whaling) vessels that have been working in the Pacific region since 1938. The records include information on all marine mammals encountered, including their species, number, location, behaviour, etc., as well as related information on hydro-meteorological observation conditions. The purpose of this database is to fill the data gap regarding the higher levels of the food web of the marine macro-ecosystem.

The next step is to create a new large database of trophic ecology, as during the comprehensive marine expeditions undertaken by the TINRO-Center, quantitative analyses are performed of the stomach contents of the catch. This data is, unfortunately, not centrally stored in a common format (which is why there is also no such corresponding database in Figure 2). Until now, it has been compiled spontaneously and randomly by individual scientists on expeditions in notebooks, and after the emergence of personal computers - in spreadsheets (often Microsoft Excel) of various sizes and formats. Collating this information into a single database will allow us to move to a qualitatively new level of data compilation, connecting the entire above-mentioned databases with the food webs of different biocenotic systems of the North Pacific.

\section{References}

[1] Adrianov, A.V. (2011) The Environmental Safety of Russia's Far Eastern Seas. Herald of the Russian Academy of Sciences, 81, 25-30. http://dx.doi.org/10.1134/S1019331611010072

[2] Shuntov, V.P., Radchenko, V.I., Dulepova, E.P. and Temnykh, O.S. (1997) Biological Resources of Economic Zone: The Structure of Pelagic and Benthic Communities, Contemporary Status, and Trends of Long Dynamics. Izvestiya TINRO, 122, 3-15. 
[3] Shuntov, V.P., Dulepova, E.P., Volvenko, I.V., Temnykh, O.S., Ivanov, O.A. and Glebov, I.I. (2007) Current Status, Structure and Productivity of Pelagic and Benthic Communities of the Far Eastern Seas Macroecosystems. Research on Marine Ecosystems and Bioresources, POI Feb RAS, Vladivostok, 502-518.

[4] Shuntov, V.P., Dulepova, E.P., Temnykh, O.S., Volkov, A.F., Naydenko, S.V., Chuchukalo, V.I. and Volvenko, I.V. (2007) State of Biological Resources in Connection with Dynamics of Macroecosystems in the Far Eastern Economic Zone of Russia. Dynamics of Marine Ecosystems and Contemporary Issues in Conservation of Biological Potential of Russian Seas, Dalnauka, Vladivostok, 75-176.

[5] Shuntov, V.P. (2013) Untimely Notices of the State of Fisheries and Fisheries Science. Bulletin No. 8 of Studying the Pacific Salmon in the Far East, TINRO-Center, Vladivostok, 226-235.

[6] FishNews (2014). http://fishnews.ru/news/22709

[7] FishNews (2015). http://fishnews.ru/news/25568

[8] Bocharov, L.N. (2004) The Perspective Approach to the Problem of People Supply with Fishery Products. Izvestiya TINRO, 138, 3-18.

[9] Bocharov, L.N. (2010) Development of Fishery Science in the Far East. Tasks and Peculiarities of the Present-Day Stage. TINRO-85, Results of the Decade. 2000-2010, TINRO-Center, Vladivostok, 3-24.

[10] Exploitation of Marine Communities (1984) In: May, R.M., Ed., Springer-Verlag, Berlin.

[11] Shuntov, V.P. (1988) Biological Resources of Far Eastern Seas: Prospects of Research and Exploitation. Biologiya Morya [Marine Biology], 3, 3-14.

[12] Shuntov, V.P. (1995) TINRO’s Ecosystem Studies of the Far Eastern Seas Biological Resources. TINRO-70, TINRO, Vladivostok, 20-31.

[13] Lapko, V.V. (2000) Ecosystem Studies of Biological Resources in TINRO-Center. TINRO-75 Years (from TONS to TINRO-Center), TINRO, Vladivostok, 146-154.

[14] Bocharov, L.N. and Shuntov, V.P. (2003) State and Tasks of the Present-Day Stage of Ecosystem Researches of Biological Resources of the Far Eastern Seas of Russia. Rational Environmental Management and Management of Marine Bioresources: Ecosystem Approach, TINRO-Center, Vladivostok, 3-8.

[15] (2004) Reports of the International Conference "Environmental Management and Management of Marine Bioresources: Ecosystem Approach”. Izvestiya TINRO, 137.

[16] Dulepova, E.P. (2005) Ecosystem Researches of TINRO-Center in the Far Eastern Seas. Izvestiya TINRO, 141, 3-29.

[17] Beamish, R.J. and Rothschild, B.J., Eds. (2009) The Future of Fisheries Science in North America. Springer Science + Business Media, Dordrecht.

[18] Bulatov, O.A. and Kotyenyov, B.N. (2012) Prospects of the Ecosystem Management of Fishery. Proceedings of AllRussia Scientific Conference Sustainable Use of Biological Resources of the Seas of Russia: Problems and Prospects, VNIRO, Moscow, 10-11.

[19] Shuntov, V.P. and Temnykh, O.S. (2013) Illusions and Realities of Ecosystem Approach to Study and Management of Marine and Oceanic Biological Resources. Izvestiya TINRO, 173, 3-29. http://dx.doi.org/10.1134/s1063074013070055

[20] Bizikov, V.A., Buyanovsky, A.I., Goncharov, S.M., Polyakov, A.V., Popov, S.B. and Sidorov, L.K. (2013) Database and Geographic Information System in the Management of Aquatic Biological Resources. Current Issues of Rational Use of Water Biological Resources, VNIRO, Moscow, 108-133.

[21] Kolesnikov, S.I. (1999) Environmental Management. Rostov State University, Rostov-on-don.

[22] Reimers, N.F. (1990) Environmental Management. Dictionary. Mysl, Moscow.

[23] Odum, E.P. (1971) Fundamentals of Ecology. Saunders Company, Philadelphia.

[24] Korobkin, V.I. and Predelsky, L.V. (2011) Ecology. Fenix, Rostov-on-don.

[25] Adrianov, A.V. and Tarasov, V.G. (2007) Present Ecological Safety in the Offshore Zones of the Far East of Russia. Dynamics of Marine Ecosystems and Present Problems of Preserving the Biological Potential of the Russian Seas, Dalnauka, Vladivostok, 177-194.

[26] Adrianov, A.V. (2013) Current Monitoring Technologies and Ensuring Environmental Safety of the Far Eastern Seas of Russia. Actual Problems of Rational Use of Water Biological Resources, VNIRO, Moscow, 47-50.

[27] Adrianov, A.V. (2014) Modern Problems of Environmental Safety of the Far Eastern Seas of Russian Federation. Marine Biodiversity and Ecosystem Dynamics of the Northwest Pacific Ocean, Science Press, Beijing, 42-66.

[28] Verenikina, E.Y. and Mazurov, Y.L. (2012) Environmental Management: The Geographic Context. Environmental Management: Theory, Practice, Education, MSU, Moscow, 32-39.

[29] Report of the World Commission on Environment and Development: Our Common Future (Brundtland Report) (1987). 
http://www.un-documents.net/our-common-future.pdf

[30] Ursul, A.D. and Romanovich, A.L. (2001) The Concept of Sustainable Development and Safety Problem. Philosophy of Science. Novosibirsk, 3, 83-105.

[31] Kasimov, N.S., Mazurov, Y.L. and Tikunov, V.S. (2004) The Concept of Sustainable Development: Its Perception in Russia. Herald of the Russian Academy of Sciences, 74, 48-55.

[32] Jenkins, G.M. and Watts, D.G. (1969) Spectral Analysis and Its Applications. Holden-Day, San Francisco.

[33] Volvenko, I.V. (2013) Ten Activity Directions of the Regional Data Center in the Federal State Unitary Enterprise “TINRO-Center”. Bulletin N 8 Study of Pacific Salmon in the Far East, TINRO-Center, Vladivostok, 95-105.

[34] Volvenko, I.V. (2014) Regional Data Center (RDC) of FSUE “TINRO-Center”: Its Principal Activities and Role in the Prediction of Fisheries Resource State. Izvestiya TINRO, 176, 3-15.

[35] Shuntov, V.P. (1998) Birds of the Far Eastern Seas of Russia. Vol. 1, TINRO, Vladivostok.

[36] Shuntov, V.P. and Ivanov, O.A. (2015) Marine Mammals in Macro-Ecosystems of Far Eastern Seas and Adjacent Waters of the North Pacific. Izvestiya TINRO, 181, 57-76.

[37] Volvenko, I.V. (2015) Dataware Support of Comprehensive Studies of Northwestern Pacific Aquatic Biological Resources. Part 1. Concept, Background, Beginning of Implementation. Trudy VNIRO, 156, 38-66.

[38] Volvenko, I.V. (2015) Dataware Support of Ccomprehensive Studies of Northwestern Pacific Aquatic Biological Resources. Part 2. Databases, Knowledge Bases, Automated Workplaces. Trudy VNIRO, 157, 71-99.

[39] Volvenko, I.V. (2015) Dataware Support of Comprehensive Studies of Northwestern Pacific Aquatic Biological Resources. Part 3. GIS, Atlases, Reference Books, Further Prospects of the Concept. Trudy VNIRO, 157, 100-126.

[40] Volvenko, I.V. and Kulik, V.V. (2011) Updated and Extended Database of the Pelagic Trawl Surveys in the Far Eastern Seas and North Pacific Ocean in 1979-2009. Russian Journal of Marine Biology, 37, 513-532. http://dx.doi.org/10.1134/S1063074011070078

[41] Volvenko, I.V. (2014) The New Large Database of the Russian Bottom Trawl Surveys in the Far Eastern Seas and the North Pacific Ocean in 1977-2010. International Journal of Environmental Monitoring and Analysis, 2, 302-312. http://www.sciencepublishinggroup.com/journal/paperinfo?journalid=162\&doi=10.11648/j.ijema.20140206.12 http://dx.doi.org/10.11648/j.ijema.20140206.12

[42] Volvenko, I.V. (2003) Data Base and GIS Technologies in Studying Nekton of the Northwest Pacific: The First Results and Perspectives. NPAFC Doc. 730, 1-17.

http://www.npafc.org/new/publications/Documents/PDF\%202003/730(Russia).pdf

[43] Volvenko, I.V. (2004) GIS for Spatial-Temporal Dynamics Analysis of the Okhotsk Sea Nekton. Izvestiya TINRO, 137, 144-176.

[44] Volvenko, I.V. (2005) GIS and Atlas of Salmons Spatial-Temporal Distribution in the Northwestern Part of the Pacific Ocean. NPAFC Doc. 879, 1-30. http://www.npafc.org/new/publications/Documents/PDF\%202005/879(Russia).pdf

[45] Volvenko, I.V. (2007) New GIS of the Pelagic Macrofauna Integrative Characteristics for the North-West Pacific. Izvestiya TINRO, 149, 3-20.

[46] Shuntov, V.P and Bocharov, L.N., Eds. (2003) Atlas of Quantitative Distribution of Nekton Species in the Okhotsk Sea. National Fish Resources, Moscow.

[47] Shuntov, V.P and Bocharov, L.N., Eds. (2004) Atlas of Quantitative Distribution of Nekton Species in the Northwestern Part of the Japan/East Sea. National Fish Resources, Moscow.

[48] Shuntov, V.P and Bocharov, L.N., Eds. (2005) Atlas of Quantitative Distribution of Nekton Species in the Northwestern Part of the Pacific Ocean. National Fish Resources, Moscow.

[49] Shuntov, V.P and Bocharov, L.N., Eds. (2006) Atlas of Quantitative Distribution of Nekton Species in the Western Part of the Bering Sea. National Fish Resources, Moscow.

[50] Shuntov, V.P and Bocharov, L.N., Eds. (2003) Nekton of the Okhotsk Sea. Tables of Abundance, Biomass and Species Ratio. TINRO-Center, Vladivostok.

[51] Shuntov, V.P and Bocharov, L.N., Eds. (2004) Nekton of the Northwestern Part of the Japan/East Sea. Tables of Abundance, Biomass and Species Ratio. TINRO-Center, Vladivostok.

[52] Shuntov, V.P and Bocharov, L.N., Eds. (2005) Nekton of the Northwestern Part of the Pacific Ocean. Tables of Abundance, Biomass and Species Ratio. TINRO-Center, Vladivostok.

[53] Shuntov, V.P and Bocharov, L.N., Eds. (2006) Nekton of the Western Part of the Bering Sea. Tables of Abundance, Biomass and Species Ratio. TINRO-Center, Vladivostok.

[54] Shuntov, V.P and Bocharov, L.N., Eds. (2012) Pelagic Macrofauna of the Western Part of the Bering Sea: Tables of 
Occurrence, Abundance and Biomass. 1982-2009. TINRO-Center, Vladivostok.

[55] Shuntov, V.P and Bocharov, L.N., Eds. (2012) Pelagic Macrofauna of the Okhotsk Sea: Tables of Occurrence, Abundance and Biomass. 1984-2009. TINRO-Center, Vladivostok.

[56] Shuntov, V.P and Bocharov, L.N., Eds. (2012) Pelagic Macrofauna of the Northwestern Part of the Pacific Ocean: Tables of Occurrence, Abundance and Biomass. 1979-2009. TINRO-Center, Vladivostok.

[57] Shuntov, V.P and Bocharov, L.N., Eds. (2014) Benthic Macrofauna of the Peter the Great Bay (Japan/East Sea): Tables of Occurrence, Abundance and Biomass. 1978-2009. TINRO-Center, Vladivostok.

[58] Shuntov, V.P and Bocharov, L.N., Eds. (2014) Benthic Macrofauna of the Western Part of the Bering Sea: Tables of Occurrence, Abundance and Biomass. 1977-2010. TINRO-Center, Vladivostok.

[59] Shuntov, V.P and Bocharov, L.N., Eds. (2014) Benthic Macrofauna of the Sea of Okhotsk: Tables of Occurrence, Abundance and Biomass. 1977-2010. TINRO-Center, Vladivostok.

[60] Shuntov, V.P and Bocharov, L.N., Eds. (2014) Benthic Macrofauna of the Northwestern Part of the Pacific Ocean: Tables of Occurrence, Abundance and Biomass. 1977-2008. TINRO-Center, Vladivostok.

[61] Shuntov, V.P and Bocharov, L.N., Eds. (2014) Benthic Macrofauna of the Northwestern Part of the Japan/East Sea: Tables of Occurrence, Abundance and Biomass. 1978-2010. TINRO-Center, Vladivostok.

[62] Volkov, A.F. and Volvenko, I.V. (2015) Net Zooplankton of the Western Part of the Bering Sea: Occurrence, Abundance, and Biomass. 1986-2013. TINRO-Center, Vladivostok. (In Press)

[63] Volkov, A.F. and Volvenko, I.V. (2015) Net Zooplankton of the Okhotsk Sea: Occurrence, Abundance, and Biomass. 1984-2013. TINRO-Center, Vladivostok. (In Press)

[64] Dolganova, N.T. and Volvenko, I.V. (2015) Net Zooplankton of the Northwestern Part of Japan (East) Sea: Occurrence, Abundance, and Biomass. 1985-2013. TINRO-Center, Vladivostok. (In Press)

[65] Dolganova, N.T. and Volvenko, I.V. (2015) Net Zooplankton of Peter the Great Bay (Japan/East Sea): Occurrence, Abundance, and Biomass. 1988-2013. TINRO-Center, Vladivostok. (In Press)

[66] Volkov, A.F. and Volvenko, I.V. (2015) Net Zooplankton of the Northwestern Pacific: Occurrence, Abundance, and Biomass. 1985-2013 TINRO-Center, Vladivostok. (In Press) 